\title{
EDUCAÇÃO DAS RELAÇÕES ÉTNICO-RACIAIS E PRÁTICA PEDAGÓGICA
}

\section{ARTIGO DE REVISÃO}

PIVA, Caroline Tito Miranda ${ }^{1}$

PIVA, Caroline Tito Miranda. Educação das relações étnico-raciais e prática pedagógica. Revista Científica Multidisciplinar Núcleo do Conhecimento. Ano 05, Ed. 04, Vol. 02, pp. 49-61. Abril de 2020. ISSN: 2448-0959, Link de acesso: https://www.nucleodoconhecimento.com.br/educacao/relacoes-etnico-raciais

\section{RESUMO}

Este artigo elucida aspectos conceituais sobre a educação das relações étnicoraciais, potencializando o diálogo transdisciplinares entre os processos políticopedagógicos e a História da África e da Cultura Afro-brasileira nos currículos da escola básica, de modo que a educação das relações étnico-raciais garanta a construção de conhecimentos contextualizados e interseccionados, que promovam uma educação antirracista, de valorização, efetivação da história e cultura africana e afro-brasileira a qual contribui para a formação humanística, a compreensão das relações sociais e o enfrentamento das desigualdades. Pretende-se pesquisar as implicações políticopedagógicas da educação das relações étnico-raciais na prática pedagógica. Para tanto, revisa-se os estudos já concretizados por Nilma Lino Gomes (2011 e 2013), Antônio Flávio Moreira (2013) e Vera Maria Candau (2013), Miguel González Arroyo

\footnotetext{
${ }^{1}$ Mestranda em Ciências da Educação, pela Universidade Grendal, polo de Teixeira de Freitas-BA. Especialista em Gestão Educacional - Faculdade Batista Brasileira (FBB). Especialista em Gestão do Trabalho Pedagógico - Universidade Vale do Cricaré (UNIVC). Especialista em Psicopedagogia Clínica e Institucional - Faculdade do Sul da Bahia (FASB). Especialista em Gestão de Políticas Públicas em Gênero e Raça - Faculdade Federal da Bahia (UFBA). Graduada em Pedagogia - Universidade do Estado da Bahia (UNEB).
} 
(2010), Beatriz Petronilha Gonçalves (2005), Ana Célia da Silva (2005), além dos documentos orientadores do Conselho Nacional de Educação (2004) e das Diretrizes Curriculares Nacionais para Educação das relações étnico-raciais (2004).

Palavras-chave: Educação, relações étnico-raciais pedagógico.

\section{INTRODUÇÃO}

Este artigo focaliza aspectos conceituais sobre a educação das relações étnicoraciais, elucidando os pontos positivos e os desafios para a prática pedagógica com a implementação da lei 10.639/03.

O presente estudo fundamenta-se nas orientações dos dispositivos legais que complementam a lei 10.639/03 como o Parecer do Conselho Nacional de Educação/Conselho Pleno 03/2004 que aprovou as Diretrizes Curriculares Nacionais para Educação das Relações Étnico-raciais; a resolução CNE/CP 01/2004 que detalha os direitos e as obrigações dos entes federados e o Plano Nacional das Diretrizes Curriculares Nacionais para a Educação das Relações Étnico-Raciais e para o ensino de História e cultura Afro-Brasileira e Africana.

A relevância em pesquisar as implicações político-pedagógicas da educação das relações étnico-raciais na prática pedagógica se dá, sobretudo, pela necessidade de uma ruptura nos moldes da educação elitista, com o objetivo de implementar, produzir e divulgar conhecimentos, atitudes, posturas e valores que possibilitem aos gestores, professores e estudantes a superação do racismo e de todas as formas de discriminação.

Tem como proposição o fato de que a educação das relações étnico-raciais se dará com a construção de conhecimentos contextualizados e interseccionados, para potencializar os diálogos inter e transdisciplinares que promovam uma educação antirracista, de valorização, efetivação da história e cultura africana e afro-brasileira a qual contribui para a formação humanística, a compreensão das relações sociais e o enfrentamento das desigualdades. 
Cumpre ressaltar que o presente trabalho procurará compreender o espaço escolar e as produções coletivas e colaborativas dos professores como fundamentais na estruturação de um Projeto Político Pedagógico que atenda adequadamente a implementação das Diretrizes Curriculares Nacionais para a Educação das Relações Étnico-Raciais, de forma que a prática pedagógica no interior das escolas seja embasada em princípios de diversidade e igualdade humana.

\section{EDUCAÇÃO DAS RELAÇÕES ÉTNICO-RACIAIS: DESAFIO PARA A PRÁTICA PEDAGÓGICA}

A Lei no 10.639, de 9 de janeiro de 2003 altera a Lei no 9.394, de 20 de dezembro de 1996, que estabelece as Diretrizes e Bases da Educação Nacional, para incluir no currículo oficial da Rede de Ensino a obrigatoriedade da temática História e Cultura Africana e Afro-Brasileira. A Lei 10.639/03 marcou uma conquista histórica do Movimento Negro em todo território nacional, relacionada à política de ações afirmativas. Mais tarde, em 2008, foi sancionada a lei 11.645/08 para incluir no currículo oficial da rede de ensino a obrigatoriedade da temática História e Cultura Afro-Brasileira e Indígena.

O processo de implementação da Lei 10.639/03 perpassa o campo das relações étnico-raciais brasileiras construído historicamente por relações de poder, no qual a raça se configura como aspecto determinante nas relações culturais, políticas, sociais e econômicas.

Para que os processos pedagógicos alcancem os objetivos da referida lei é necessário no contexto escolar 0 entendimento dos conceitos de raça e etnia. Segundo o parecer do Conselho Nacional de Educação 03 de 2004:

É importante destacar que se entende por raça a construção social forjada nas tensas relações entre brancos e negros, muitas vezes simuladas como harmoniosas, nada tendo a ver com o conceito biológico de raça cunhado no século XVIII e hoje sobejamente superado (BRASIL, 2004a, p. 5). 
O conceito de raça determinava durante muito tempo nas relações sociais brasileiras os aspectos físicos de uma pessoa, enfatizando a ideia de raças superiores e inferiores utilizadas pela ciência do século XIX. No entanto, o Movimento Negro ressignificou o termo raça utilizando-o com um sentido político e de reconhecimento da tradição africana. Conforme Gomes:

O conceito de raça é adotado, nessa perspectiva, com um significado político e identitário construído com base na análise do tipo de racismo que existe no contexto brasileiro, as suas formas de superação e considerando a dimensão histórica e cultural a que esse processo complexo nos remete (GOMES, 2011, p. 2).

Sendo assim, as raças passam a ser consideradas construções sociais, políticas e culturais marcadas pelas relações de poder ao longo do processo histórico. É nas relações sociais que as diferenças são percebidas e hierarquizadas, e estas relações determinam o lugar social de cada um na sociedade brasileira.

De acordo com os estudos apresentados por Heilbom; Araújo e Barreto (Orgs.) (2011), do curso As discussões sobre as questões raciais chegaram atrasadas ao Brasil, pois a noção de raça vinha sendo discutida na Europa desde o início do século XIX e dividia teóricos por diferentes ideias.

As pessoas negras e amarelas eram definidas biológica, moral e intelectualmente como inferiores aos brancos, sendo a miscigenação interpretada como algo que enfraquecia os grupos. A solução encontrada para a questão racial no Brasil foi o embranquecimento, ou seja, o ingresso de imigrantes europeus no país, com sua ascendência racial desejada.

Na década de 1930, a ideia de democracia racial infelizmente ganha força no Brasil com a obra Casa-grande e Senzala, do sociólogo Gilberto Freire que enfatizava um convívio harmônico entre brancos, negros e indígenas.

No entanto, a Frente Negra Brasileira (FNB) surgiu em São Paulo nos anos de 1930 e teve filiais por todo o interior do estado paulista e em outras capitais, como Salvador, 
Porto Alegre e Recife. Os ativistas negros denunciavam a situação vivenciada pela população negra que, por um lado, não havia recebido qualquer tipo de auxílio do Estado brasileiro no pós-abolição e, de outro, era preterida no mercado de trabalho, já que os empregadores privilegiavam imigrantes europeus para os postos de trabalho disponíveis.

Mesmo assim, o imaginário de democracia racial tomava cada vez mais força e começava a significar sinônimo de Brasil. Assim, após a segunda guerra mundial surge o campo de investigações sociológicas que buscava a relação entre raça e classe.

Uma série de pesquisas conhecidas como "O ciclo de estudos da UNESCO" (19531956) foi responsável por oportunizar a profissionalização e a institucionalização das ciências sociais brasileiras, além de cientificamente comprovar as denúncias de existência de racismo e preconceito racial no país.

Já as pesquisas que surgiram no final da década de 1970 enfatizavam que as questões de classe, não são prioritárias para justificar as enormes desigualdades entre brancos e negros. Segundo o sociólogo Carlos Hasenbalg no seu estudo Discriminação e Desigualdades Raciais no Brasil:

Delimita a mudança de enfoque em relação ao tratamento do problema racial brasileiro. $O$ autor tira a ênfase do legado do escravismo como explicação das relações raciais hoje, e aponta o racismo e a discriminação pós-abolição como causadores principais da subordinação social dos negros (HASENBALG, 1979 apud HEILBOM; ARAÚJO; BARRETO (Orgs.), 2011, p.105).

Ao deixar de lado os estudos pioneiros do chamado "Projeto UNESCO" e os trabalhos da chamada "escola paulista de relações raciais" (Florestan Fernandes, Fernando Henrique Cardoso e Octávio lanni), a tradição de pesquisa desenvolvida nos últimos trinta anos dá forte sustentação a ideia de que os brasileiros negros estão expostos a desvantagens cumulativas ao longo das fases do ciclo de vida individual e que essas 
desvantagens são transmitidas de uma geração a outra. Nesse contexto, como afirma Gomes (2005) "O conceito de etnia ganha força para identificar que os grupos humanos não são marcados por características biológicas, mas por processos históricos e culturais".

O termo étnico-racial apresenta as questões relacionadas tanto às características físicas, como às culturais, políticas e identitárias da população negra brasileira. Dessa forma, a educação das relações étnico-raciais exige novas aprendizagens. Em consonância com estas ideias, o parecer do Conselho Nacional de Educação 03 de 2004, enfatiza:

Para reeducar as relações étnico-raciais, no Brasil, é necessário fazer emergir as dores e medos que têm sido gerados. É preciso entender que o sucesso de uns tem o preço da marginalização e da desigualdade impostas a outros. E então decidir que sociedade queremos construir daqui para frente (BRASIL, 2004a, p. 5).

Para que fossem incluídos no sistema escolar conteúdos/atividades relacionadas à temática da História e Cultura Afro-Brasileira e Africana, em 09 de janeiro de 2003 entrou em vigor a Lei Federal 10.639 que alterou os artigos 26-A e 79-B, da Lei de Diretrizes e Bases da Educação Nacional (LDB) ํo 9.394/96 determinando a obrigatoriedade de estudos relacionados à temática acima, passando a vigorar com as seguintes modificações:

Art. 26-A. Nos estabelecimentos de ensino fundamental e médio, oficiais e particulares, torna-se obrigatório o ensino sobre História e Cultura Afro Brasileira.

$\S 1^{\circ} \mathrm{O}$ conteúdo programático a que se refere o caput deste artigo incluirá o estudo da História da África e dos Africanos, a luta dos negros no Brasil, a cultura negra brasileira e o negro na formação da sociedade nacional, resgatando a contribuição do povo negro nas áreas social, econômica e política pertinente à História do Brasil. 
$\S 2^{\circ}$ Os conteúdos referentes à História e Cultura Afro-Brasileira serão ministrados no âmbito de todo o currículo escolar, em especial nas áreas de Educação Artística e de Literatura e História Brasileiras.

Art. 79-B. O calendário escolar incluirá o dia 20 de novembro como Dia Nacional da Consciência Negra (BRASIL, 2003).

Nesta perspectiva, a escola tem uma grande responsabilidade para com a implementação da lei $10.639 / 03$, pois a mesma legitimou todo o processo histórico vivenciado pelo negro, abrindo espaço para a construção de uma pedagogia da diversidade que supere as discriminações ao oportunizar o acesso ao conhecimento das diferentes culturas e ao desenvolver ações afirmativas de valorização e reconhecimento da história e cultura afro-brasileira. A este respeito Silva afirma:

Estudar as Africanidades Brasileiras significa tomar conhecimento, observar, analisar um jeito peculiar de ver a vida, o mundo, o trabalho, de conviver e de lutar pela dignidade própria, bem como pela de todos descendentes de africanos, mais ainda de todos que a sociedade marginaliza. Significa também conhecer e compreender os trabalhos e criatividade dos africanos e de seus descendentes no Brasil, e de situar tais produções na construção da nação brasileira (SILVA, 2005, p. 156).

De acordo com as Diretrizes Curriculares Nacionais para a Educação das Relações Étnico-raciais e para o Ensino de História e Cultura Afro-brasileira e Africana[2], o sucesso de pedagogias de combate ao racismo e de todas as formas de discriminação depende da desconstrução de alguns conceitos e estereótipos formados historicamente na perspectiva de uma sociedade marcada pela hierarquização das diferenças. O primeiro deles é a preocupação com a utilização do termo negro ou preto. Esta preocupação ocorre devido à utilização negativa do termo negro pelos senhores para nomear os escravos. Contudo, este foi ressignificado pelo Movimento Negro dando-Ihe um sentido político e positivo. O Instituto Brasileiro de Geografia e Estatística usa o termo preto, assim como branco, pardo e indígena para classificar a cor da população brasileira. 
Atualmente, ser negro no Brasil tem um caráter positivo de reconhecimento e pertencimento a um grupo de pessoas com clara opção política carregada de significados historicamente construídos pela cultura territorial, mítica e identitária dos africanos e afro-brasileiros. De acordo com Silva:

Identificar e corrigir a ideologia, ensinar que a diferença pode ser bela, que a diversidade é enriquecedora e não é sinônimo de desigualdade, é um dos passos para a reconstrução da autoestima, do auto conceito, da cidadania e da abertura para o acolhimento dos valores das diversas culturas presentes na sociedade (SILVA, 2005, p. 31).

Após a abolição, baseado na ideologia do branqueamento que pregava a superioridade da raça branca, o governo brasileiro incentivou a vinda de imigrantes para o país com o objetivo de dizimar os indígenas, negros e mestiços. Na atualidade, percebe-se ainda a repercussão de tal ideologia no imaginário tanto de brancos como dos próprios negros que repetem o preconceito e a discriminação, por se considerarem inferiores. Segundo Gomes:

A educação para as relações étnico-raciais que cumpre com seu papel é aquela em que as crianças, os adolescentes, os jovens, e os adultos negros e brancos, ao passarem pela escola básica, questionem a si mesmos nos seus próprios preconceitos, tornem-se dispostos a mudar posturas e práticas discriminatórias, reconheçam a beleza e a riqueza das diferenças e compreendam como essas foram transformadas em desigualdades nas relações de poder e de dominação (GOMES, 2013, p. 83).

Indubitavelmente, o mito da democracia racial, a ideologia do branqueamento e o racismo permearam a formação histórica da sociedade brasileira com o pressuposto da universalidade e igualdade de direitos para todos os cidadãos. No entanto, desconstruir essa lógica requer um diálogo constante e crítico entre a pedagogia multirracial e o sistema político. Corroborando Miguel Arroyo afirma: 
Como pensar políticas para a diversidade se o pressuposto estruturante do sistema é que todos em abstrato são iguais? Para o sistema, por décadas, não existe nem diversidade nem racismo na escola, vista como instituição e espaço por excelência da democracia racial. A concepção de igualdade e universalidade com que o sistema escolar se auto identifica, deveria merecer uma atenção especial no diálogo entre pedagogia multirracial popular e o sistema. A mesma concepção igualitária e universalista inspira o pensamento pedagógico, as didáticas e as teorias do currículo e os cursos de formação. O diálogo aí é igualmente difícil e tenso. (ARROYO, 2010, p. 116).

O Movimento Negro revelou a necessidade de políticas afirmativas que garantam a superação do racismo e todas as formas de discriminação. Nesse contexto, a lei $10.639 / 03$, posteriormente alterada pela $11.645 / 08$, caracterizada como uma lei afirmativa, impulsiona mudanças significativas na educação das relações étnicoraciais.

Para atender as exigências dos dispositivos legais, as unidades de ensino precisam rever seus projetos político-pedagógicos e suas propostas curriculares baseadas nas orientações das Diretrizes Curriculares Nacionais para educação das relações étnicoraciais, que tem como princípios norteadores: a consciência política e histórica da diversidade, o fortalecimento de identidades e de direitos e a promoção de ações educativas de combate ao racismo e a discriminação. Segundo as Diretrizes Curriculares Nacionais[3] (BRASIL, 2004) tais princípios encaminham as práticas pedagógicas para:

- À Igualdade básica de pessoa humana como sujeito de direitos;

- À compreensão de que a sociedade é formada por pessoas que pertencem a grupos étnico-raciais distintos, que possuem cultura e história próprias, igualmente valiosas e que em conjunto constroem, na nação brasileira, sua história;

- Ao conhecimento e à valorização da história dos povos africanos e da cultura afro-brasileira na construção histórica e cultural brasileira; 
- À superação da indiferença, injustiça e desqualificação com que os negros, os povos indígenas e as classes populares às quais os negros, no geral, pertencem, são comumente tratados;

- À desconstrução, por meio de questionamentos e análises críticas, objetivando eliminar conceitos, ideias, comportamentos veiculados pela ideologia do branqueamento, pelo mito da democracia racial, que tanto mal fazem a negros e brancos;

- À busca, da parte de pessoas, em particular de professores não familiarizados com a análise das relações étnico-raciais e sociais com o estudo de história e cultura afro-brasileira e africana, de informações e subsídios que Ihes permitam formular concepções não baseadas em preconceitos e construir ações respeitosas;

- Ao diálogo, via fundamental para entendimento entre diferentes, com a finalidade de negociações, tendo em vista objetivos comuns, visando a uma sociedade justa.

- Ao desencadeamento de processo de afirmação de identidades, de historicidade negada ou distorcida;

- Ao rompimento com imagens negativas forjadas por diferentes meios de comunicação, contra os negros e os povos indígenas;

- Aos esclarecimentos a respeito de equívocos quanto a uma identidade humana universal;

- Ao combate à privação e violação de direitos;

- À ampliação do acesso a informações sobre a diversidade da nação brasileira e sobre a recriação das identidades, provocada por relações étnico-raciais;

- Às excelentes condições de formação e de instrução que precisam ser oferecidas, nos diferentes níveis e modalidades de ensino, em todos os estabelecimentos, inclusive os localizados nas chamadas periferias urbanas e nas zonas rurais.

Dessa forma, é importante pensar a educação, o conhecimento, a escola, o currículo a serviço de um projeto de sociedade democrática, justa e igualitária. Um ideal de 
sociedade que avança na cultura política, social e pedagógica. Uma sociedade que garanta os direitos humanos para todos. A este respeito Nilma Lino Gomes afirma:

Estamos diante de um contexto que vai além da implementação de uma legislação que responda às demandas históricas de um movimento social. A Lei 10.639/03 faz parte das políticas de ação afirmativa. Estas têm como objetivo central a correção de desigualdades, a construção de oportunidades iguais para os grupos sociais e étnico-raciais com um comprovado histórico de exclusão e primam pelo reconhecimento e valorização da história, da cultura e da identidade desses segmentos (GOMES, 2013, p. 79).

Dessa forma, observa-se a necessidade de dar visibilidade aos aspectos históricos culturais dos afro-brasileiros, de forma que os estudantes se identifiquem e se reconheçam. O trabalho pedagógico precisa estimular a pesquisa do processo histórico que perpassa as relações étnico-raciais de forma a identificar as raízes africanas da comunidade.

Diante do ideal de construir essa sociedade, é necessário superar toda prática e toda cultura seletiva, excludente, segregadora e classificatória na organização do conhecimento, dos tempos e espaços, dos agrupamentos dos educandos e também na organização do convívio e do trabalho dos educadores e dos educandos. A este respeito, Moreira e Câmara afirmam:

Em termos políticos, a ênfase na identidade deriva do reconhecimento de que certos grupos sociais têm, há muito, sido alvo de inaceitáveis discriminações. Entre eles, incluem-se os negros, as mulheres e os homossexuais. Tais grupos se têm rebelado contra a situação de opressão que os têm vitimado e, por meio de árduas lutas, têm conquistado espaços e afirmado seus direitos à cidadania. (MOREIRA; CÂMARA, 2013, p. 39). 
Questionar sobre a percepção dos diversos sujeitos que atravessam a escola traz à tona a necessidade de se examinar os currículos educacionais da atualidade. A educação básica, ainda hoje, se estrutura tendo como base a transmissão de conceitos, o que ocasiona uma aprendizagem frágil, que nem sempre oportuniza ao estudante a compreensão do seu contexto histórico e social, muito menos dando-Ihe a possibilidade de intervir adequadamente nesta sociedade.

Hoje está consciência do caráter homogeneizador e monocultural da escola é cada vez mais forte, assim como a consciência da necessidade de romper com está e construir práticas educativas em que a questão da diferença e do multiculturalismo se façam cada vez mais presentes (CANDAU, 2013, p. 15).

Nesse sentido, a educação das relações étnico-raciais deve ser o resultado da luta política voltada para a construção de uma escola e de práticas pedagógicas que insiram a diversidade, promovam a reflexão, a mudança de postura, estimulando práticas coletivas de combate ao racismo e à discriminação.

\section{CONCLUSÃO}

Nota-se, ao finalizar este artigo, que a homologação da lei 10.639/03, posteriormente da lei 11.645/2008, juntamente com a resolução 01/2004 e o parecer 03/2004 do Conselho Nacional de Educação, garantiram a inclusão da educação das relações étnico-raciais na escola e incentivaram a produção de material pedagógico, instituindo as responsabilidades dos estabelecimentos de ensino e oferecendo orientações pedagógicas voltadas para o desenvolvimento de um currículo intercultural.

Muitos avanços foram conquistados, todavia é grande o desafio para se incluir na proposta curricular conteúdos referentes à História e cultura Afro-brasileira e Africana devido ao imaginário marcado por uma história onde a diferença é sinônimo de desigualdade. 
Dessa forma, é indispensável que os processos político-pedagógicos da educação das relações étnico-raciais sejam fortemente analisados, discutidos e implementados com a participação de toda comunidade escolar, com vistas a desenvolver uma prática pedagógica que tem como objetivo central a valorização e respeito às pessoas negras e indígenas, sua cultura e sua história; tendo como premissas o questionamento das relações baseadas em preconceitos; a análise da forma como os negros e outras minorias são representadas nos textos, materiais didáticos e conteúdos escolares; buscando desenvolver atividades educativas de combate ao racismo e a discriminação.

\section{REFERÊNCIAS}

ARROYO, Miguel González. A pedagogia multirracial popular e o sistema escolar. In: GOMES, Nilma Lino (Org.). Um olhar além das fronteiras: educação e relações raciais. $1^{\underline{a}}$ edição. Belo Horizonte: Autêntica, 2010. p. 111-130.

BRASIL, Lei o 9394 de 20 de dezembro de 1996. Estabelece as Diretrizes e Bases da Educação Nacional. Diário Oficial da República Federativa do Brasil, Poder Executivo, Brasília, DF, 23 de dez. 1996.

. Lei no 10.639 de 9 de janeiro de 2003. Altera a Lei o 9.394, de 20 de dezembro de 1996, que estabelece as diretrizes e bases da educação nacional, para incluir no currículo oficial da Rede de Ensino a obrigatoriedade da temática "História e Cultura Afro-Brasileira", e dá outras providências. Diário Oficial da República Federativa do Brasil, Poder Executivo, Brasília, DF, 10 jan. 2003.

Parecer no 03/2004 CNE/CP. Institui Diretrizes Curriculares Nacionais para a Educação das Relações Étnico-Raciais e para o Ensino da História Afro-Brasileira e africana. Diário Oficial da União, Brasília, 10 de mar. de 2004. Disponível em: $<$ http://portal.mec.gov.br/cne/arquivos/pdf/003.pdf>. Acesso em: 20 out. 2019. 
. Resolução no 01/2004 CNE/CP. Detalha os direitos e obrigações dos entes federados frente à implementação da Lei 10639/03. Diário Oficial da União, Brasília, 17 de jun. de 2004 .

Diretrizes Curriculares Nacionais para a Educação das Relações ÉtnicoRaciais e para o Ensino da História Afro-Brasileira e Africana. Brasília: SECADI/MEC, out. 2004.

CANDAU, Vera Maria. Multiculturalismo e educação: desafios para a prática pedagógica. In: MOREIRA, Antônio Flávio Barbosa; CANDAU, Vera Maria (orgs.). Multiculturalismo: diferenças culturais e práticas pedagógicas. 10.ed. Petrópolis, RJ: Vozes, 2013. p. 13-37.

GOMES, Nilma Lino. Educação, relações étnico-raciais e a Lei 10.639/03. Portal Geledés: Instituto $\mathrm{Da}$ Mulher Negra, 2011. Disponível em: https://www.geledes.org.br/educacao-relacoes-etnico-raciais-e-lei-10-63903-2/. Acesso em: 13 jun. 2019.

Nilma Lino. A questão racial na escola: desafios colocados pela implementação da Lei 10.639/03. In: MOREIRA, Antônio Flávio Barbosa; CANDAU, Vera Maria (orgs.). Multiculturalismo: diferenças culturais e práticas pedagógicas. 10.ed. Petrópolis, RJ: Vozes, 2013. p. 67-89.

HASENBALG, 1979 apud HEILBOM, Maria Luiza; ARAÚJO, Leila; BARRETO, Andreia (Orgs.). Gestão de Políticas Públicas em Gênero e Raça/GPP - GeR: módulo III. Rio de Janeiro: CEPESC; Brasilia: Secretária de Políticas para as Mulheres, 2011, p.105- 125 .

HEILBOM, Maria Luiza; ARAÚJO, Leila; BARRETO, Andreia (Orgs.). Gestão de Políticas Públicas em Gênero e Raça/GPP - GeR: módulo III. Rio de Janeiro: CEPESC; Brasilia: Secretária de Políticas para as Mulheres, 2011.

MOREIRA, Antônio Flávio; CÂMARA, Michelle Januário. Reflexões sobre currículo e identidade: implicações para a prática pedagógica. In: MOREIRA, Antônio Flávio 
Barbosa; CANDAU, Vera Maria (Orgs.). Multiculturalismo: diferenças culturais e práticas pedagógicas. 10.ed. Petrópolis, RJ: Vozes, 2013. p. 38-66.

SILVA, Petronilha Beatriz Gonçalves e. Aprendizagem e ensino das africanidades brasileiras. In: MUNANGA, Kabengele (Org.). Superando o racismo na escola. $2^{\mathrm{a}}$ edição. Brasília: Ministério da Educação, Secretaria de Educação Continuada, Alfabetização e Diversidade, 2005. p. 155-172.

\section{APÊNDICE - REFERÊNCIAS DE NOTA DE RODAPÉ}

2. BRASIL. Diretrizes Curriculares Nacionais para a Educação das Relações ÉtnicoRaciais e para o Ensino da História Afro-Brasileira e Africana. Brasília: SECADI/MEC, out. 2004.

3. BRASIL. Diretrizes Curriculares Nacionais para a Educação das Relações ÉtnicoRaciais e para o Ensino da História Afro-Brasileira e Africana. Brasília: SECADI/MEC, out. 2004.

Enviado: Janeiro, 2020.

Aprovado: Abril, 2020. 